\title{
The Development of Models for Carbon Dioxide Reduction Technologies for Spacecraft Air Revitalization
}

\author{
Michael J. Swickrath* and Molly Anderson \\ ${ }^{\dagger}$ NASA Johnson Space Center, Houston, TX, 77058
}

\begin{abstract}
Through the respiration process, humans consume oxygen $\left(\mathrm{O}_{2}\right)$ while producing carbon dioxide $\left(\mathrm{CO}_{2}\right)$ and water $\left(\mathrm{H}_{2} \mathrm{O}\right)$ as byproducts. For long term space exploration, $\mathrm{CO}_{2}$ concentration in the atmosphere must be managed to prevent hypercapnia. Moreover, $\mathrm{CO}_{2}$ can be used as a source of oxygen through chemical reduction serving to minimize the amount of oxygen required at launch. Reduction can be achieved through a number of techniques. The National Aeronautics and Space Administration (NASA) is currently exploring the Sabatier reaction, the Bosch reaction, and co-electrolysis of $\mathrm{CO}_{2}$ and $\mathrm{H}_{2} \mathrm{O}$ for this process. Proof-of-concept experiments and prototype units for all three processes have proven capable of returning useful commodities for space exploration.

While all three techniques have demonstrated the capacity to reduce $\mathrm{CO}_{2}$ in the laboratory, there is interest in understanding how all three techniques would perform at a system-level within a spacecraft. Consequently, there is an impetus to develop predictive models for these processes that can be readily re-scaled and integrated into larger system models. Such analysis tools provide the ability to evaluate each technique on a comparable basis with respect to processing rates. This manuscript describes the current models for the carbon dioxide reduction processes under parallel developmental efforts. Comparison to experimental data is provided were available for verification purposes.
\end{abstract}

*Analyst, Crew and Thermal Systems Division, 2101 NASA Parkway, EC211, Houston, TX, 77058, AIAA Member.

${ }^{\dagger}$ Analysis Lead, Crew and Thermal Systems Division, 2101 NASA Parkway, EC211, Houston, TX, 77058, AIAA Member. 